\title{
Demographic and Economic Predictors of Uptake of Cervical Cancer Screening among Women in Isiolo County, Kenya
}

\author{
Agnes Muthoni Linus ${ }^{1}$, Anthony Wanyoro ${ }^{2} \&$ Mary Muiruri Gitahi ${ }^{1}$ \\ ${ }^{1}$ School of Public Health and Applied Human Sciences, Kenyatta University, Kenya \\ ${ }^{2}$ School of Medicine, Kenyatta University, Kenya \\ Correspondence: Agnes Muthoni; School of Public Health and Applied Human Sciences, Kenyatta University, \\ Kenya.Tel:+254-712-951-784. E-mail: agnesmutuma1@gmail.com
}

Received: September 25, 2021 Accepted: October 26, 2021 Online Published: November 8, 2021

doi:10.5539/gjhs.v13n12p72

URL: https://doi.org/10.5539/gjhs.v13n12p72

\begin{abstract}
Purpose: To determine the demographic and economic factors associated with cervical cancer screening among women in Isiolo County, Kenya.

Methodology: A community based cross-sectional study. The study included 444 women aged 15-65 years drawn from six community units in Isiolo County. Multistage cluster sampling was used to draw a sample from the community units and household levels. Data was collected using a questionnaire administered by a research assistant. The questionnaire consisted of the demographic and economic factors associated with uptake of cervical cancer screening. Descriptive statistics, cross tabulations and multivariate logistic regressions were used in data analysis.

Findings: Among the 444 eligible women 81(18.2\%) had ever been screened for cervical cancer. The significant determinants of screening included residence $(\mathrm{OR}=0.012$, CI 95\% [0.002-0.06] $\mathrm{P}-\mathrm{p}<0.001)$; education $(\mathrm{OR}=0.31$, CI 95\% [0.107-0.895] $\mathrm{p}<0.05)$; Occupation ( $\mathrm{OR}=0.142$, CI 95\% [0.031-0.66] P-Value $=0.013)$; and perception by the respondents that screening is expensive $(\mathrm{OR}=0.112 \mathrm{CI} 95 \%$ [0.04-0.309] P-Value $<0.001)$.

Conclusion: Uptake of cervical cancer screening at Isiolo county is significantly low. This study identified the demographic factors of screening as area of residence and education level. Occupation and the respondents' opinion that screening is expensive were found to reduce chances of screening among the women. Many of the participants however expressed their willingness to be screened if the service was offered for free. Intensifying health education and community awareness is recommended to equip the women with accurate information regarding cervical cancer and screening.
\end{abstract}

Keywords: cervical cancer, community unit, demographic factors, economic factors, screening uptake

\section{Introduction}

Cervical cancer is ranked fourth in morbidity and mortality globally with a reported incidence of 570,000 cases in 2018 and a mortality of 311,365 annually. Reports indicate that $85 \%$ of these cases are found in the developing nations such as those in sub Saharan Africa (Bray et al., 2018). The World Health Organization (WHO) places cervical cancer as the second most common cancer among women in Kenya ("Kenya: Human Papillomavirus and Related Cancers, Fact Sheet 2017," 2017) where approximately 5250 (12.9\%) cases of cervical cancer and 3286 $(11.8 \%)$ deaths reported in 2018. The incidence is projected to be two times more by 2025 (Kimani et al., 2012).

Abnormal cell growth in the cervix is often associated with infection by human papilloma viruses (HPV). Infection with one or more of the 15 high risk cancerous types often results in invasive cervical cancer after 10-20 years. About $70 \%$ of cervical cancer cases reported globally are caused by HPV types 16 and 18 (National-Cancer-Screening-Guidelines-2018.Pdf, n.d.). Since cervical cancer is a slowly growing disease, it's advancement through precancerous changes provides chances for prevention, detection and early treatment. Effective screening programs in the developed nations has raised the level of screening to over 50\% among women of reproductive age as compared to the developing nations with only 5\% level of uptake (Rosser, Hamisi, et al., 2015).

The various tests used to detect cervical cancer include; cytology (Pap smear and liquid cytology), HPV DNA tests, visual inspection with acetic acid (VIA) and visual inspection lugol's iodine (VILLI). Visual inspection tests with 
3\%-5\% acetic acid (VIA) and/or Lugol's iodine (VILI) appear to be a satisfactory screening approach especially in poor resource settings (Catarino et al., 2015). These tests are simple, cost-effective with relative ease of use and may be performed by various healthcare practitioners (physicians, nurse, midwives and technicians). The visible changes that occur in the cervix after application of acetic acid are immediate, and can be classified as negative or positive for cervical neoplasia. These immediate results facilitate a same-day screen and management strategy. Therefore, this allows most of the eligible women to participate in the programme by minimizing repeat visits. Evidence shows that this single-visit approach leads to the most significant decrease in high-grade cervical intraepithelial neoplasia (CIN and it is regarded safe, acceptable and fairly effective in Sub-Saharan Africa

It is worth noting that the low and middle-income countries lack high-quality cancer registry data, which is a basis for planning and implementing evidence-based cancer control programs (Bray et al., 2018)

Various challenges prevent women from seeking early screening. In a study carried out in Ethiopia, it was realized that there is a close relationship between socio-economic status and cervical cancer. Such socioeconomic factors include; education, income and occupation (Tadesse, 2015). A similar study in Cameron identified some of the socio economic determinants of screening as: age, level of education, residence, marital status, age at first sexual, intercourse, number of sexual partners, number of pregnancies and number of deliveries (Fru et al., 2020). Even though the relationship between cervical and socio economic variables is not a direct one, it has a considerable effect for the exposure to the Human Papilloma Virus and development of cervical cancer (Tadesse, 2015).

In Kenya, the level of uptake of cervical cancer screening is low at $16.4 \%$ although the service is available across the health facilities (Kimani et al., 2012). Lack of and low levels of screening exposes women to cervical cancer with most presenting at late stages with invasive and advanced cervical cancer. Isiolo County reported a low screening level of 5.4\% between 2017 and 2018 in contrast to the expected $70 \%$ coverage stipulated by the National Cancer Screening Guidelines (National-Cancer-Screening-Guidelines-2018.Pdf, n.d.).

While cervical cancer screening can effectively reduce morbidity and deaths occurring as a result of cervical cancer, the uptake of screening in Isiolo is low. Hospital based data indicate that just $5.4 \%$ of women were screened between 2017-2018 in Isiolo County. Among those screened, 2.4\% had a positive VIA/VILLI result. The women who test positive for VIA/VILLI have a likelihood of progressing to cervical cancer. Studies have shown that there is a close relationship among socio-economic status, socio demographic characteristics and the uptake of cervical cancer screening among communities (Tadesse, 2015; Fru et al., 2020). This study sought to determine the demographic and economic determinants of the uptake of cervical cancer screening among women in Isiolo county. The objective of the study was to determine the factors associated with the uptake of cervical cancer screening among women in Isiolo County. Specifically, to determine the current level of uptake of cervical cancer screening among women in Isiolo County and to establish the demographic-economic factors associated with uptake of cervical cancer screening among women in Isiolo County.

\section{Materials and Methods}

This was a cross-sectional study where quantitative data was collected using a structured interviewer administered questionnaire to obtain data on participants screening status and their demographics and economics. The study was carried out in Isiolo County in Kenya which has three Sub-Counties, namely; Isiolo, Merti and Garbatulla. Study participants were women who resided in Isiolo and met the inclusion criteria. A sample size of 444 respondents was determined using the Cochran's formula (Heinisch, 1965) at a confidence interval of 95\% and a margin error of $5 \%$. The proportion of women of reproductive age expected to have been screened is assumed to be 0.5 .

Multistage sampling method was used. All the three Sub counties of Isiolo County were purposively selected. Primary health care services at the basic community level are offered through the community units. Out of the 40 community units in the county, 6 community units were randomly selected for this study. The six community units had a total of 4663 households. Random sampling was done to get a representative proportionate sample per community unit to make a total of 444 households. Random number selection was done to identify the first household for the study and there after every $11^{\text {th }}$ household to make a total of 444 households.

All women who met the criteria for cervical cancer screening as stipulated in the Kenya National Cancer Screening Guidelines, 2018 were included in the study. They included; residents of Isiolo, women who has ever had sexual intercourse, women aged 25 to 49 years and those aged 50-65 years.

We obtained ethical clearance from Kenyatta University Ethical Review Committee Informed consent was sought from respondents and we ensured confidentiality, privacy and autonomy. Data was entered, coded and analyzed using Statistical Package for Social Sciences (SPSS) version 25.0. Relationship between the level of uptake of screening for cervical cancer and the independent variables were tested using Chi-square. Logistic regression 
model was fitted for all significant variables.

\section{Results}

3.1 Uptake of Cervical Cancer Screening

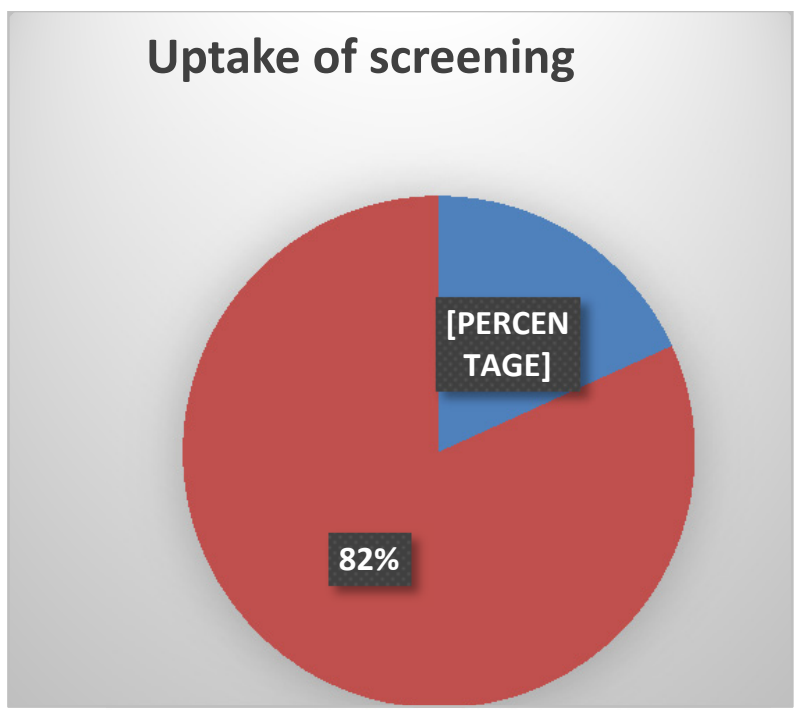

Figure 1. Uptake of Cervical Cancer Screening

Figure 1 indicates the uptake of cervical cancer screening in Isiolo County at the period of study.

Out of the 444 respondents, 81 had ever been screened (18.2\%). Majority of those screened were from Isiolo sub county (59) while the lowest screened were residents of Merti South (4).

\subsection{Demographic Characteristics of the Respondents}

Table 1. Demographic characteristics of the respondents

\begin{tabular}{llcc}
\hline Variables & & Frequency $(\mathrm{n}=444)$ & Percent (\%) \\
\hline Subcounty & Isiolo & 201 & 45.3 \\
& Garba Tulla & 125 & 28.2 \\
& Merti & 118 & 26.6 \\
\hline Age in Years & $15-24$ & 90 & 20.3 \\
& $25-34$ & 186 & 41.9 \\
& $35-44$ & 132 & 29.7 \\
& $45-54$ & 23 & 5.2 \\
& $55-64$ & 13 & 2.9 \\
\hline Highest educational level & Primary & 225 & 50.7 \\
& Secondary & 65 & 14.6 \\
& Post-Secondary & 30 & 6.8 \\
& Non formal & 124 & 27.9 \\
\hline Marital status & Married & 365 & 82.2 \\
& Widowed & 19 & 4.3 \\
& Single & 60 & 13.5 \\
\hline Number of children & $0-4$ children & 278 & 62.6 \\
& 5 and above & 140 & 31.5 \\
& Not stated & 26 & 5.9 \\
\hline
\end{tabular}


Table 1 indicates the frequencies of the respondents' demographic variables.

Most of the respondents were aged between 25-34 years (41.9\%). A total of 78.6\% of the women had no formal or up to primary level of education. Majority of the women were married, $82.2 \%$ while $94.1 \%$ had ever given birth. For those who had given birth, 33.4\% had five children and above.

\subsection{Economic Characteristics and Respondents' Perceptions about Cost of Screening}

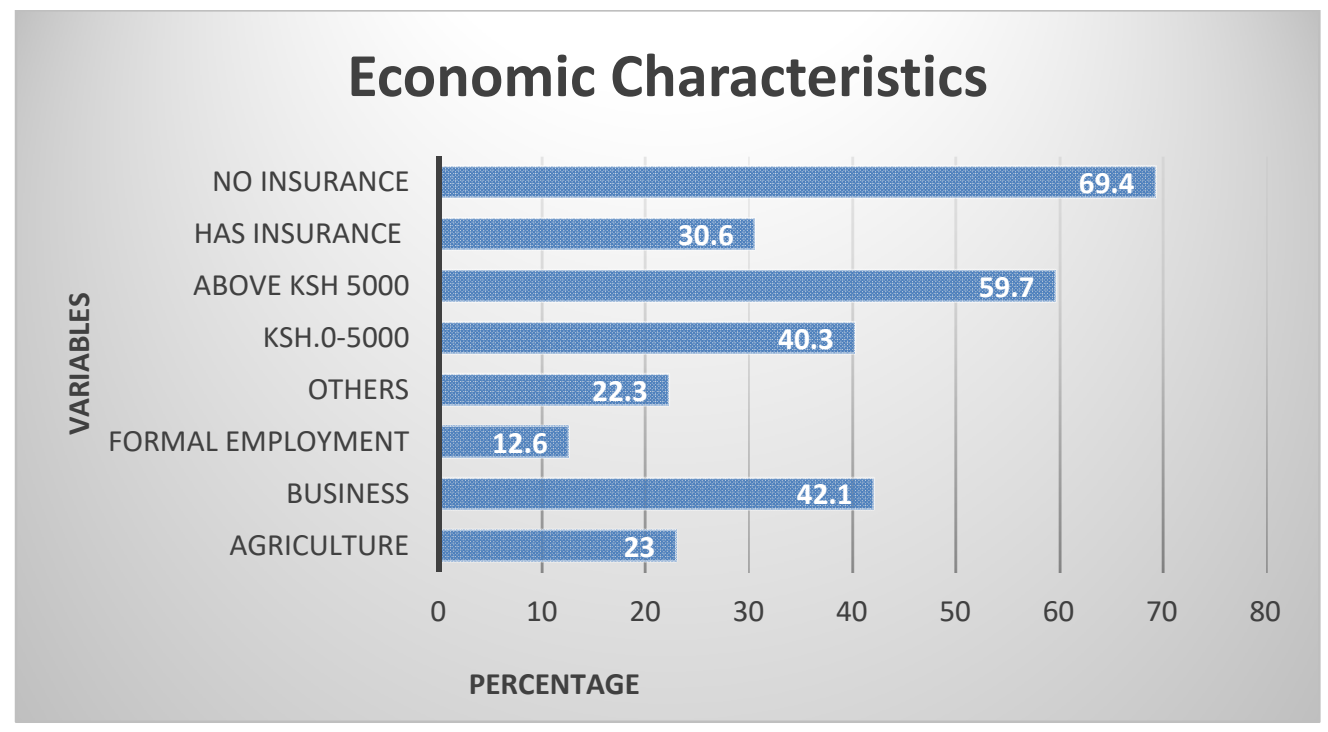

Figure 2. Economic characteristics of the respondents

Figure 2 outlines the occupation, income and medical insurance cover of the respondents.

Majority were business people (42.1\%) with $59.7 \%$ indicating that they had an income of over KSH.5000 per month. Only $30.6 \%$ of the respondents had an insurance cover.

\subsection{Respondents' Perception of the Cost of Screening and Willingness to be Screened for Free}

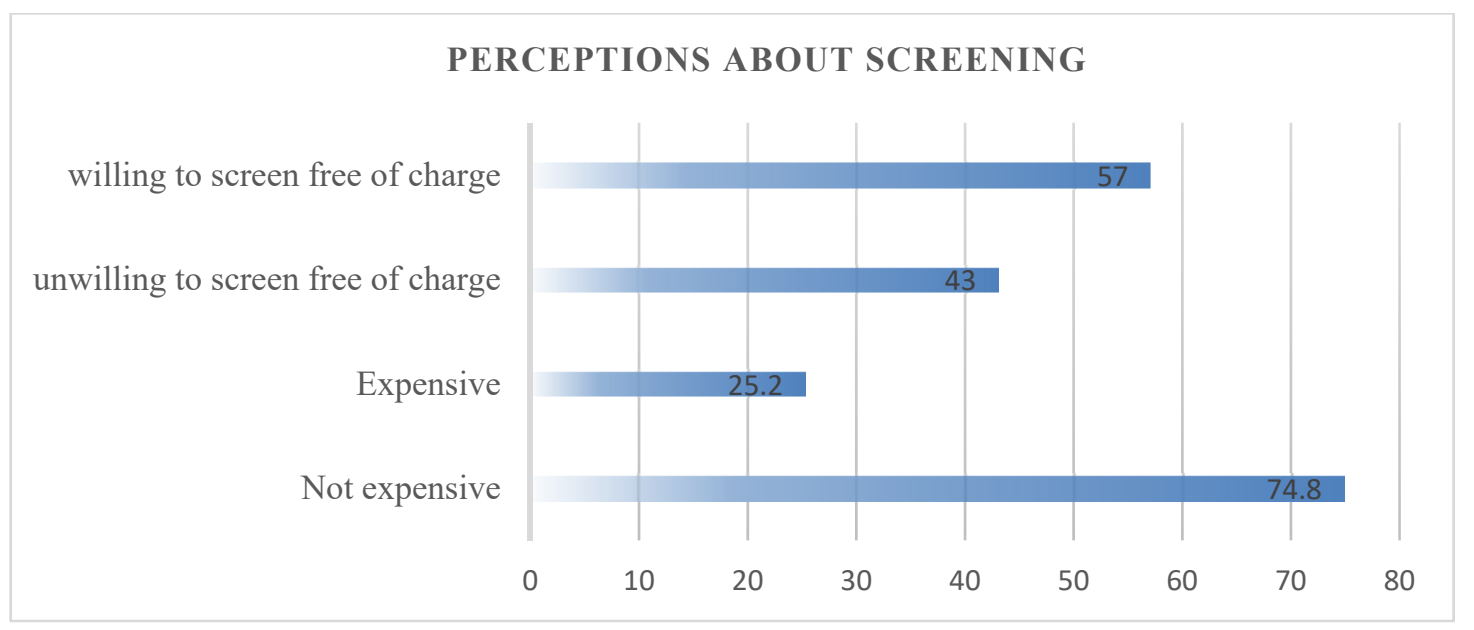

Figure 3. Respondents' perceptions towards cost and willingness to be screened

As indicated in figure $3.25 .2 \%$ of the respondents agreed that screening for cervical cancer is expensive while $57 \%$ expressed willingness to be screened if service is offered for free. 


\subsection{Influence of Demographic Factors on Uptake of Cervical Cancer Screening}

Table 2. Influence of demographic factors on uptake of cervical cancer screening

\begin{tabular}{|c|c|c|c|c|c|c|}
\hline Variables & & screened & Not-screened & value & df & p-value \\
\hline \multirow{3}{*}{ subcounty } & Isiolo & $59(72.8 \%)$ & $142(39.1 \%)$ & \multirow{3}{*}{35.3} & \multirow{3}{*}{2} & \multirow{3}{*}{0.000} \\
\hline & Garbatulla & $18(22,2 \%)$ & $107(29.5 \%)$ & & & \\
\hline & Merti & $4(4.9 \%)$ & $114(31.4 \%)$ & & & \\
\hline \multirow{5}{*}{ Age in years } & $15-24$ & $6(7.4 \%)$ & $84(23.1 \%)$ & \multirow{5}{*}{11.58} & \multirow{5}{*}{4} & \multirow{5}{*}{0.021} \\
\hline & $25-34$ & $37(45.7 \%)$ & $149(41.0 \%)$ & & & \\
\hline & $35-44$ & $30(37.0)$ & $102(28.1)$ & & & \\
\hline & $45-54$ & $4(4.9 \%)$ & $19(5.2 \%)$ & & & \\
\hline & $55-64$ & $4(4.9 \%)$ & $9(2.5 \%)$ & & & \\
\hline \multirow{4}{*}{ Highest educational level } & primary & $39(17.3 \%)$ & $186(82.7 \%)$ & \multirow{4}{*}{19.65} & \multirow{4}{*}{3} & \multirow{4}{*}{0.000} \\
\hline & secondary & $13(20.0 \%)$ & $52(80.05 \%)$ & & & \\
\hline & Post-secondary & $14(46.7 \%)$ & $16(53.3 \%)$ & & & \\
\hline & Non formal & $15(12.1 \%)$ & $109(87.9 \%)$ & & & \\
\hline \multirow{3}{*}{ Marital status } & married & $58(71.6 \%)$ & $307(84.6 \%)$ & \multirow{3}{*}{13.401} & \multirow{3}{*}{2} & \multirow{3}{*}{0.001} \\
\hline & single & $21(25.9 \%)$ & $39(10.7 \%)$ & & & \\
\hline & widowed & $2(2.5 \%)$ & $17(4.7 \%)$ & & & \\
\hline \multirow{3}{*}{ Number of children } & $0-4$ children & $54(66.7 \%)$ & $224(61.7 \%)$ & \multirow{3}{*}{6.16} & \multirow{3}{*}{2} & \multirow{3}{*}{0.046} \\
\hline & 5 and above & $27(33.3 \%)$ & $113(31.1 \%)$ & & & \\
\hline & No children & $0(0 \%)$ & $26(7.2 \%)$ & & & \\
\hline
\end{tabular}

Table 2 shows that there is a significant relationship between residence and uptake of screening for cervical cancer.

Those who reside in Isiolo sub-county had 29.4\% screened while those in Merti Sub County had 3.4\%. ( $\chi 2$ $=35.326, \mathrm{df}=2$ P-Value $=0.000$ ).

Majority of those screened were aged between $25-44$ years $(82.7 \%)$ indicating a significant association between age and Uptake of screening $(\chi 2=11.584, \mathrm{df}=4 \mathrm{P}$-Value $=0.021)$.

Level of education had a significant relationship with uptake of cervical cancer screening with $46.7 \%$ of those who had attained post-secondary education having been screened. Those with no formal education were the least screened at $12.1 \%\left(\chi^{2}=19.65, \mathrm{df}=3 \mathrm{P}\right.$-Value $\left.=0.000\right)$.

Married women were significantly associated with screening with $71.6 \%$ of married women having been screened in comparison to low levels of screening by widowed and single women $(\chi 2=13.401, \mathrm{df}=2 \mathrm{P}$-Value $=0.001)$. Women with four and below children were mostly screened, $66.7 \%$, at a significant value of $(\chi 2=6.16, \mathrm{df}=2$ P-Value=0.046). 


\subsection{Economic Factors Influencing Uptake of Screening}

Table 3. Economic factors influencing uptake of screening

\begin{tabular}{|c|c|c|c|c|c|c|}
\hline Variables & & screened & Not-screened & value & df & p-value \\
\hline \multirow{2}{*}{ Health insurance cover } & Yes & $35(43.2 \%)$ & $101(27.8 \%)$ & \multirow{2}{*}{7.3} & \multirow{2}{*}{1} & \multirow{2}{*}{0.007} \\
\hline & No & $46(56.8 \%)$ & $262(72.2 \%)$ & & & \\
\hline \multirow{4}{*}{ Occupation } & Agriculture & $12(14.8 \%)$ & $90(24.8 \%)$ & \multirow{4}{*}{22.9} & \multirow{4}{*}{3} & \multirow{4}{*}{0.000} \\
\hline & Business & $36(44.4 \%)$ & $151(41.6 \%)$ & & & \\
\hline & Formal employment & $22(27.2 \%)$ & $34(9.4 \%)$ & & & \\
\hline & Others & $11(13.6 \%)$ & $88(24.2 \%)$ & & & \\
\hline \multirow{2}{*}{ Income } & $0-5000$ & $21(25.9 \%)$ & $158(43.5 \%)$ & \multirow{2}{*}{8.5} & \multirow{2}{*}{1} & \multirow{2}{*}{0.004} \\
\hline & Above 5000 & $60(74.1 \%)$ & $205(56.5 \%)$ & & & \\
\hline \multirow{2}{*}{ Perception screening is expensive } & Disagree & $70(86.4 \%)$ & $262(72.2 \%)$ & \multirow{2}{*}{7.1} & \multirow{2}{*}{1} & \multirow{2}{*}{0.008} \\
\hline & Agree & $11(13.6 \%)$ & $101(27.8 \%)$ & & & \\
\hline \multirow{2}{*}{ Willingness to be screened for free } & Disagree & $11(13.6 \%)$ & $70(84.6 \%)$ & \multirow{2}{*}{3.5} & \multirow{2}{*}{1} & \multirow{2}{*}{0.000} \\
\hline & Agree & $180(49.6 \%)$ & $183(50.4 \%)$ & & & \\
\hline
\end{tabular}

Table 3 outlines the influence of health insurance cover, occupation and income of the respondents on the uptake of cervical cancer screening. There was a significant relationship between having a health insurance cover and uptake of screening $(\chi 2=7.3, \mathrm{df}=1, \mathrm{P}-\mathrm{Value}=0.007)$. The respondent's occupation was significantly associated with uptake of screening $(\chi 2=17.1, \mathrm{df}=1, \mathrm{P}$-Value $<0.000)$ as well as monthly income $(\chi 2=8.5, \mathrm{df}=1, \mathrm{P}$-value $=0.004)$. Perception that screening is expensive was significant with $86.4 \%$ of those who disagreed that it is expensive having been screening $(\chi 2=7.1, \mathrm{df}=1, \mathrm{P}$-value $=0.008)$. Willingness to be screened if the service is offered for free was significantly associated with screening $(\chi 2=35, \mathrm{df}=1$, P-value $<0.000)$.

\subsection{Predictors of Uptake of Cervical Cancer Screening}

Table 4. Predictors of screening

\begin{tabular}{|c|c|c|c|c|c|c|c|c|}
\hline \multirow{2}{*}{ Variable } & \multirow{2}{*}{ B } & \multirow{2}{*}{ S.E. } & \multirow{2}{*}{ Wald } & \multirow{2}{*}{ df } & \multirow{2}{*}{ Sig. } & \multirow{2}{*}{$\operatorname{Exp}(B)$} & \multicolumn{2}{|c|}{ 95\% C.I.for EXP(B) } \\
\hline & & & & & & & Lower & Upper \\
\hline Isiolo (RC) & & & 42.12 & 2 & 0.000 & & & \\
\hline Garbatulla & -3.735 & 0.702 & 28.324 & 1 & 0.000 & 0.024 & 0.006 & 0.094 \\
\hline Merti & -1.301 & 0.711 & 3.347 & 1 & 0.067 & 0.272 & 0.067 & 1.097 \\
\hline Primary (RC) & & & 10.45 & 3 & 0.015 & & & \\
\hline Secondary & -1.304 & 0.497 & 6.873 & 1 & 0.009 & 0.272 & 0.102 & 0.72 \\
\hline Post-secondary & -1.065 & 0.712 & 2.236 & 1 & 0.135 & 0.345 & 0.085 & 1.392 \\
\hline Non formal & -2.547 & 0.893 & 8.125 & 1 & 0.004 & 0.078 & 0.014 & 0.451 \\
\hline \multicolumn{9}{|l|}{ Below5(RC) } \\
\hline 5 and above & -0.166 & 0.092 & 3.23 & 1 & 0.072 & 0.847 & 0.707 & 1.015 \\
\hline \multicolumn{9}{|l|}{ Has insurance } \\
\hline No insurance & -0.143 & 0.427 & 0.113 & 1 & 0.737 & 0.866 & 0.375 & 2 \\
\hline Agriculture (RC) & & & 8.943 & 3 & 0.03 & & & \\
\hline Business & -0.901 & 0.585 & 2.366 & 1 & 0.124 & 0.406 & 0.129 & 1.28 \\
\hline Formal employment & -0.6 & 0.474 & 1.597 & 1 & 0.206 & 0.549 & 0.217 & 1.391 \\
\hline
\end{tabular}




\begin{tabular}{lcccccccc}
\hline Others & -1.965 & 0.678 & 8.406 & 1 & 0.004 & 0.14 & 0.037 & 0.529 \\
\hline $\begin{array}{l}\text { O-5000(RC) } \\
\text { Over 5000 }\end{array}$ & 0.656 & 0.399 & 2.708 & 1 & 0.1 & 1.928 & 0.882 & 4.212 \\
\hline $\begin{array}{l}\text { Inexpensive (RC) } \\
\text { Expensive }\end{array}$ & -2.367 & 0.459 & 26.592 & 1 & 0.000 & 0.094 & 0.038 & 0.231 \\
\hline $\begin{array}{l}\text { Not willing (RC) } \\
\text { Willing }\end{array}$ & 2.284 & 0.47 & 23.563 & 1 & 0.000 & 9.813 & 3.903 & 24.676 \\
\hline Single (RC) & & & 3.254 & 2 & 0.196 & & & 4.152 \\
Married & 0.569 & 0.436 & 1.702 & 1 & 0.192 & 1.766 & 0.751 & 44.573 \\
Widowed & 1.727 & 1.056 & 2.674 & 1 & 0.102 & 5.625 & 0.71 & \\
\hline Constant & 7.056 & 1.253 & 31.729 & 1 & 0 & 1159.601 & & \\
\hline
\end{tabular}

In Table 4, an assessment of the independent effect of all significant factors influencing cervical cancer screening in Isiolo County was done by fitting a logistic regression with the significant factors in the model. Residents of Garbatulla were 0.024 times less likely to be screened compared to those from Isiolo Sub- County. (OR=0. 024, CI 95\% [0.0.006-0.094] P-Value $<0.001$ ). Women with non-formal education were 0.078 less likely to be screened than those with primary level of education. Educated women were more likely to seek screening than those with no education at all especially those with secondary levels of education respectively (OR=0.078, CI 95\% [0.014-0.451] $\mathrm{P}$-Value $=0.004)$. Those with other forms of employment were 0.14 times less likely to be screened than those in agriculture $(\mathrm{OR}=0.142$, CI 95\% [0.037-0.529] P-Value $=0.004)$. Respondents who thought that screening is expensive were 0.09 less likely to be screened than those who thought screening is inexpensive (OR $=0.094 \mathrm{CI} 95 \%$ [0.038-0.231] P-Value $<0.001)$. The respondents who wished not to be screened even if the service was offered for free were 9.813 times more likely to be screened than those who agreed (OR=9.813 CI 95\% [3.903-24.676 P-Value $<0.001$ ). This model could explain up to $49.2 \%$ of the variations in the uptake of cervical cancer screening. Other factors were not statistically significant.

\section{Discussion}

Out of the 444 respondents, $81(18.2 \%)$ had ever been screened for cervical cancer. The rate of screening is much lower than the expected national target of 70\% stipulated in the Kenya National screening guidelines, 2018. In a Kenya step wise survey done in 2015 it was revealed that only $11.3 \%$ of women had ever been screened for cervical cancer. Out of those screened, 16.4\% were aged 30-49 years (Ministry-of-Health-Referral-Strategy1.Pdf, n.d.).Other studies in Kenya have also indicated that uptake of cervical cancer screening is low (Were et al., 2011; Tiruneh et al., 2017; Agnes Muthoni, 2016).

Majority of the women who reported having been screened were from the urban setting, Isiolo subcounty with 59 (72.8\%). Merti subcounty had the lowest uptake of screening with only 4(4.9\%) of the women having been screened. Merti Sub County is an area that is basically rural in setting compared to Isiolo Sub County where all the county offices and social amenities are located. Screening for cervical cancer has been noted to be higher in urban areas than in rural areas (Rosser, Njoroge, et al., 2015).

We found out that majority of women who were screened were between ages 25-44 years which falls within the National Cancer Screening Guidelines (National-Cancer-Screening-Guidelines-2018.Pdf, n.d.-a). Early marriages are common in Isiolo and only 6 (7.4\%) of those aged 15-24 years (90) had ever been screened for cervical cancer.

Education had a significant influence on cervical cancer screening with secondary education being positively associated with uptake of cervical cancer screening. A study by Tiruneh et al. found out that education equips the women with knowledge of cervical cancer disease thus increasing the acceptance of screening (Tiruneh et al., 2017). A study in Senegal indicated that women with education are likely to seek screening services as compared to uneducated ones (Khadim et al., 2020). In Isiolo where illiteracy levels are high, only 15 (12.1\%) of the study participant were screened compared to $46.7 \%$ of those who had attained post-secondary education having been screened.

Marital status was positively associated with screening with 58 (71.6\%) of married women being screened. A study on factors influencing cervical cancer screening in India, identified married women as the most clients utilizing screening services An explanation to this scenario could the perception that unmarried women are not at 
the right phase to seek reproductive health services (Singh \& Badaya, 2012).

We found that parity was a significant factor in screening with $100 \%$ of the women who said that they had given birth indicating that they had undergone screening. An explanation for high uptake among those women who have ever given birth is that they have had previous contact with reproductive health services (Singh \& Badaya, 2012). Formal employment was found to be an important predictor of screening among the women. This could be associated with high level of education needed for one to achieve formal employment in the country. These results are consistent with a study in Ethiopia which identified an association between economic variables, women's level of education, income, and occupation and cervical cancer. The women's perception of screening being expensive and willingness to be screened were significant predictors to being screened. Being aware of the cost of screening is important as it determines the affordability of screening services by women. Most women were positive about being screened and were willing to take be screened when the service is offered. Similar perception was as well noted during a study in Uganda where the women expressed their readiness to be screened when services were availed (Mukama et al., 2017).

\section{Conclusion}

The results of this study revealed that cervical cancer screening uptake is low in Isiolo county. The determinants of cervical cancer screening included residence, education level, occupation and respondents' thought that screening is expensive. Further there was a significant positive predictor to screening where the respondents felt that screening is expensive.

\section{Recommendations}

This study recommends an intensified collaboration between education and devolved health ministry in order to improve education levels in the county. Targeted health education on the importance of cervical cancer screening would increase the uptake. The women should also be made aware of the cost of screening services as it determines the affordability of the service.

\section{Ethical Approval}

Ethical clearance was obtained from Ethical Review Committee and authorization to conduct the study was obtained from National Commission for Science Technology and Innovation (ref.no. 858649)

\section{Competing Interests Statement}

The authors declare that there are no competing or potential conflicts of interest.

\section{References}

Agnes Muthoni, M. (2016). Socio-Demographic Characteristics Influencing Uptake of Screening for Cervical Cancer in Women Aged 18-49 Years in Imenti North Sub-county, Meru County, Kenya. Science Journal of Public Health, 4(2), 94. https://doi.org/10.11648/j.sjph.20160402.13

Bray, F., Ferlay, J., Soerjomataram, I., Siegel, R. L., Torre, L. A., \& Jemal, A. (2018). Global cancer statistics 2018: GLOBOCAN estimates of incidence and mortality worldwide for 36 cancers in 185 countries. CA: A Cancer Journal for Clinicians, 68(6), 394-424. https://doi.org/10.3322/caac.21492

Catarino, R., Petignat, P., Dongui, G., \& Vassilakos, P. (2015). Cervical cancer screening in developing countries at a crossroad: Emerging technologies and policy choices. World Journal of Clinical Oncology, 6(6), 281-290. https://doi.org/10.5306/wjco.v6.i6.281

Fru, C. N., Andrew, T., Cho, F. N., Tassang, T., \& Fru, P. N. (2020a). Socio-economic Determinants Influencing Cervical Cancer Screening in Buea: A Cross-Sectional Study. International Journal of TROPICAL DISEASE \& Health, 14-22. https://doi.org/10.9734/ijtdh/2020/v41i1130331

Heinisch, O. (1965). Cochran, W. G.: Sampling Techniques, 2. Aufl. John Wiley and Sons, New York, London 1963. Preis s. Biometrische Zeitschrift, 7(3), 203-203. https://doi.org/10.1002/bimj.19650070312

Kenya: Human Papillomavirus and Related Cancers, Fact Sheet 2017. (2017). Fact Sheet, 2.

Khadim, N., Diegane, T. J. A., Ousmane, T., Toly, L., Bintou, D. F., Ibra, D. A., Adama, F., \& Papa, N. (2020). Factors Associated with the Use of Cervical Cancer Screening in the Mbour Health District (Senegal). Open Journal of Obstetrics and Gynecology, 10(04), 604-614. https://doi.org/10.4236/ojog.2020.1040054

Kimani, F., Sharif, S. K., \& Bashir, I. (2012). Ministry of Public Health and Sanitation and Ministry of Medical Services National Cervical Cancer Prevention Program in Kenya: Strategic Plan 2012-2015. Nairobi. Nairobi, Kenya. 
Ministry-of-Health-Referral-Strategyl.pdf. $\quad$ (n.d.). Retrieved $\quad$ September $\quad 4, \quad 2021$, from http://guidelines.health.go.ke:8000/media/Ministry-of-Health-Referral-Strategy1.pdf

Mukama, T., Ndejjo, R., Musabyimana, A., Halage, A. A., \& Musoke, D. (2017). Women's knowledge and attitudes towards cervical cancer prevention: A cross sectional study in Eastern Uganda. BMC Women's Health, 17(1), 9. https://doi.org/10.1186/s12905-017-0365-3

National-Cancer-Screening-Guidelines-2018.pdf. (n.d.-a). Retrieved May 24, 2021, from https://www.health.go.ke/wp-content/uploads/2019/02/National-Cancer-Screening-Guidelines-2018.pdf

Rosser, J. I., Hamisi, S., Njoroge, B., \& Huchko, M. J. (2015). Barriers to Cervical Cancer Screening in Rural Kenya: Perspectives from a Provider Survey. Journal of Community Health, 40(4), 756-761. https://doi.org/10.1007/s10900-015-9996-1

Rosser, J. I., Njoroge, B., \& Huchko, M. J. (2015). Cervical Cancer Screening Knowledge and Behavior among Women Attending an Urban HIV Clinic in Western Kenya. Journal of Cancer Education, 30(3), 567-572. https://doi.org/10.1007/s13187-014-0787-7

Singh, S., \& Badaya, S. (2012). Factors Influencing uptake of Cervical Cancer Screening among Women in India: A Hospital based Pilot Study. Journal of Community Medicine \& Health Education. https://doi.org/10.4172/2161-0711.1000157

Tadesse, S. K. (2015a). Socio-economic and cultural vulnerabilities to cervical cancer and challenges faced by patients attending care at Tikur Anbessa Hospital: A cross sectional and qualitative study. BMC Women's Health, 15(1), 75. https://doi.org/10.1186/s12905-015-0231-0

Tiruneh, F. N., Chuang, K.-Y., Ntenda, P. A. M., \& Chuang, Y.-C. (2017). Individual-level and community-level determinants of cervical cancer screening among Kenyan women: A multilevel analysis of a Nationwide survey. BMC Women's Health, 17(1), 109. https://doi.org/10.1186/s12905-017-0469-9

Were, E., Nyaberi, Z., \& Buziba, N. (2011). Perceptions of risk and barriers to cervical cancer screening at Moi Teaching and Referral Hospital (MTRH), Eldoret, Kenya. African Health Sciences, 11(1). https://doi.org/10.4314/ahs.v11i1.64993

\section{Copyrights}

Copyright for this article is retained by the author(s), with first publication rights granted to the journal.

This is an open-access article distributed under the terms and conditions of the Creative Commons Attribution license (http://creativecommons.org/licenses/by/4.0/). 